\title{
Enfermedades infecciosas endémicas, emergentes y re- emergentes en Yucatán a principios del Siglo XXI*.
}

\section{Simposio}

Renán A. Góngora-Biachi, Carlos J. Castro-Sansores, Pedro González-Martínez, Guadalupe Ayora-Talavera, María A. Loroño-Pino, José A. Farfán-Ale.

Centro de Investigaciones Regionales "Dr. Hideyo Noguchi", Universidad Autónoma de Yucatán, Mérida, Yucatán, México.

\section{LAS ENFERMEDADES ENDÉMICAS, EMERGENTES Y RE-EMERGENTES COMO UN PROBLEMA DE SALUD EN YUCATÁN.}

\section{RA Góngora-Biachi.}

Puede definirse una enfermedad infecciosa endémica como aquella que prevalece en forma continua o cíclica en una región geográfica específica. La magnitud de su presencia depende tanto de factores extrínsecos al agente etiológico -como por ejemplo cambios climáticos, expansión de población de vectores, nivel de susceptibilidad de la población, etc., así como de factores intrínsecos al agente infeccioso (virulencia, mutaciones que confieran resistencia a drogas, etc.).

Por otro lado, una enfermedad re-emergente se define como aquella que ha existido previamente, pero rápidamente se incrementa en incidencia o extensión geográfica (1). Un buen ejemplo de este tipo de enfermedad es el cólera. Sin embargo, si la enfermedad infecciosa es nueva y aparece o se identifica en una población determinada, entonces debe considerarse una enfermedad infecciosa emergente (2).

Desde 1970 se han detectado al menos treinta nuevas enfermedades infecciosa emergentes en el ámbito mundial (3), entre otras: el SIDA, la hepatitis C, la enfermedad de Lyme, la Eschericha Colli 0157:H7, hantavirus, criptosporidium, el virus de influenza H5N1. También desde 1970, otras enfermedades se han imbricado a las endémicas en ciertas regiones del mundo: cólera, paludismo y tuberculosis resistentes, plaga, Ébola, entre otros (3).

El proceso de emergencia de una enfermedad infecciosa ocurre en dos pasos (4): 1) introducción a una nueva población y 2) establecimiento y diseminación (adopción). La emergencia de enfermedades infecciosas se ve favorecida por factores condicionantes, que se describen en el cuadro I.

En Yucatán pueden identificarse algunos factores condicionantes que favorecen o han favorecido la emergencia, re-emergencia y el mantenimiento endémico de las enfermedades infecciosas. El cuadro II describe estos factores.

*Simposio efectuado el 15 y 16 de noviembre de 2001 en el Centro de Investigaciones Regionales "Dr. Hideyo Noguchi" de la Universidad Autónoma de Yucatán, Mérida, Yucatán, México.

Solicitud de sobretiros: M.C. Renán A. Góngora-Biachi, Laboratorio de Hematología, Centro de Investigaciones Regionales "Dr. Hideyo Noguchi", Universidad Autónoma de Yucatán, Ave. Itzáes No. 490 x 59, C.P. 97000, Mérida, Yucatán, México. Tel.: (999) 928-41-57 Fax: (999) 923-61-20. E-mail: gbiachi@tunku.uady.mx. 
RA Góngora-Biachi, CJ Castro-Sansores, P González-Martínez y col.

\section{Cuadro I}

Factores condicionantes de las enfermedades infecciosas emergentes y re-emergentes.

\begin{tabular}{ll}
\hline Cambios ecológicos & $\begin{array}{l}\text { Agricultura } \\
\text { Ecosistemas de agua } \\
\text { Deforestación } \\
\text { Diques } \\
\text { Cambios climáticos }\end{array}$ \\
$\begin{array}{ll}\text { Crecimientopoblacional } \\
\text { Humana } \\
\text { Migración } \\
\text { Guerra, conflictos civiles } \\
\text { Degradación urbana } \\
\text { Conducta sexual, } \\
\text { Drogadicciónintravenosa }\end{array}$ \\
$\begin{array}{ll}\text { Viajes internacionales } \\
\text { Comercio, Tecnología e Industria }\end{array}$ & $\begin{array}{l}\text { Alimentos procesados } \\
\text { Transplantes de órganos } \\
\text { Nuevos antimicrobianos }\end{array}$ \\
$\begin{array}{ll}\text { Adaptación y cambios microbiales } \\
\text { Ruptura de las medidas de salud pública } \\
\text { Bioterrorismo }\end{array}$ \\
\hline
\end{tabular}

En el caso del Virus de la Inmunodeficiencia Humana (VIH) originalmente el turismo internacional y el hecho de que personas residentes de Yucatán se trasladaran a los EE.UU. fue la causa del inicio de la epidemia en esta región (5). Recientemente, la migración para fines laborales hacia los EE.UU. está representando un factor cada vez más importante en la dinámica de diseminación de este virus, sobre todo en la región citrícola (sur) del estado de Yucatán. La drogadicción intravenosa ha jugado un papel casi nula en diseminación del VIH y este hecho ha impedido que las mujeres trabajadoras del sexo no se hayan infectado, a pesar de sus prácticas riesgosas sin protección adecuada (6). De hecho la epidemia se sigue manteniendo por las prácticas sexuales de tipo homosexual en hombres homosexuales y bisexuales. Las mujeres han sido víctimas de esta condición epidemiológica (7).

El Virus Linfotrópico de Células T Humanas tipo II (HTLV-II) es un retrovirus endémico en Yucatán y ha sido catalogado como un arqueovirus (8). La prevalencia en población general mayor de 18 años es de $0.3 \%$ (9) y el reservorio principal son las mujeres sexo-trabajadoras (10), condición que favorece su diseminación. Al parecer la transfusión sanguínea no participa en la diseminación de este retrovirus (11), sin embargo la lactancia materna sí (12). Recientemente hemos encontrado una mayor prevalencia de infección del HTLV-II que en la población general en los pacientes con infección por el VIH.

Cuadro II

Factores condicionantes de enfermedades infecciosas endémicas, emergentes y re-emergentes en Yucatán, México.

\begin{tabular}{|c|c|}
\hline Enfermedades & Factores Predisponentes \\
\hline VIH/SIDA & $\begin{array}{l}\text { Turismo } \\
\text { Migración laboral } \\
\text { Conductas sexuales } \\
\text { Transmisión vertical }\end{array}$ \\
\hline $\begin{array}{l}\text { Virus linfotrópico de } \\
\text { células T Humanas tipo II }\end{array}$ & $\begin{array}{l}\text { Comercio sexual } \\
\text { Transfusión sanguínea } \\
\text { Lactancia materna } \\
\text { VIH/SIDA }\end{array}$ \\
\hline Dengue & $\begin{array}{l}\text { Urbanización, transportación, migración } \\
\text { Resurgimiento del vector } \\
\text { Cambios climáticos } \\
\text { Campañas preventivas inoportunas }\end{array}$ \\
\hline Influenza & $\begin{array}{l}\text { Aves migratorias } \\
\text { Porcicultura } \\
\text { Turismo y movimientos migratorios } \\
\text { Cambios climáticos }\end{array}$ \\
\hline Hepatitis B y C & $\begin{array}{l}\text { Incremento en número de transfusiones, } \\
\text { programas de hemodiálisis y transplantes renales. } \\
\text { Conducta sexual } \\
\text { Malas condiciones higiénicas y } \\
\text { hacinamiento en zonas peri-urbanas y rurales. } \\
\text { Urbanización } \\
\text { Cambios sociales: guarderías }\end{array}$ \\
\hline Rotavirus & $\begin{array}{l}\text { Cambios climáticos } \\
\text { ¿Cambios virales? }\end{array}$ \\
\hline Leptospira & $\begin{array}{l}\text { Piscicultura } \\
\text { Reservorios: ratas, perros, pájaros. } \\
\text { Contaminación del agua } \\
\text { Deforestación } \\
\text { ¿Actividad eco-turística? }\end{array}$ \\
\hline & SIDA \\
\hline Tuberculosis resistente & $\begin{array}{l}\text { Programa de atención y vigilancia } \\
\text { Control de infecciones nosocomiales } \\
\text { Esquemas terapéuticos inadecuados }\end{array}$ \\
\hline Virus del Oeste del Nilo & $\begin{array}{l}\text { Aves migratorias } \\
\text { Brote epidemiológico en Florida } \\
\text { Presencia del vector } \\
\text { Movimientos migratorios }\end{array}$ \\
\hline
\end{tabular}

El virus del Dengue es ya endémico en la región y su permanencia y aparición de todos los serotipos 


\section{Enfermedades infecciosas endémicas, emergentes y re-emergentes en Yucatán.}

se ve favorecida por condiciones como la urbanización, la transportación Inter.-regional, el resurgimiento del vector, los cambios climáticos que favorecen lluvias extemporáneas y la puesta en práctica de campañas preventivas inoportunas.

\section{Cuadro III}

Enfermedades infecciosas potencialmente emergentes en Yucatán, México.

Cólera
Dengue hemorrágico
Erlichiosis
Tifo endémico
Hantavirus
Cryptosporidiosis
Malaria resistente
Estafilococo resistente a vancomicina
Micobacterium avium intracelular
Fiebre amarilla
Cepas de VIH resistentes

Los virus de la hepatitis B y C son endémicos y su persistencia en la región se ha favorecido por el incremento del número de transfusiones sanguíneas, el incremento de procedimientos de hemodiálisis, los programas de transplante renal, el incremento de conductas sexuales promiscuas y la persistencia de condiciones higiénicas sub-óptimas.

Los brotes de rotavirus en Yucatán se han asociado a urbanización, el incremento de guarderías, cambios climáticos y probablemente la emergencia de cepas mutadas.

La posibilidad de emergencias de serotipos nuevos del virus de influenza humana se ven favorecidos en Yucatán por la migración de patos silvestres, la porcicultura y los movimientos migratorios. Por otro lado, los brotes del virus de influenza en Yucatán no dependen de la época invernal como en las zonas templadas, por lo que su persistencia durante todo el año favorece su condición endémica.

La leptospirosis es otra enfermedad endémica con posibilidad de re-emergencia favorecida por el desarrollo de la piscicultura, la presencia de reservorios (ratas, perros, pájaros), contaminación de agua, la deforestación y las actividades eco-turísticas.

La tuberculosis resistente es una condición aún no identificada en Yucatán para octubre de 2001. Sin embargo hay condicionantes que pueden provocar la emergencia de este problema: la epidemia de SIDA, deficiencias en los programas de atención y vigilancia epidemiológica de esta infección, un control efectivo de infecciones nosocomiales y la disponibilidad de esquemas terapéuticos efectivos.

Un brote ocurrido en Nueva York del Virus del Oeste del Nilo en 1999 puso de manifiesto la presencia de este virus en el continente americano (13). La diseminación geográfica hasta la Florida en octubre d 2001, el hecho de que Yucatán es parte de la ruta de aves migratorias, la presencia de vector (mosquitos Culex) y los movimientos migratorios turísticos entre la Florida y Yucatán, son condicionantes que favorecerían la presencia de este virus en Yucatán.

Otro grupo de enfermedades infecciosas potencialmente emergentes o re-emergentes en Yucatán se señalan en el cuadro III.

La investigación de las enfermedades infecciosas endémicas, emergentes y re-emergentes debe considerarse una acción prioritaria y el resultado de la suma de esfuerzos de instituciones de salud, académicas y de la industria biotecnológicafarmacéutica. De esta forma podrá hacerse un frente efectivo que detenga su avance.

\section{LA DINÁMICA EPIDEMIOLÓGICA DEL VIH/ SIDA EN YUCATÁN: UN ANÁLISIS DE 1983 A 2001.}

\section{J Castro-Sansores.}

Dos años después de haberse reportado los primeros casos del síndrome de inmunodeficiencia adquirida (SIDA) en los Estados Unidos de Norteamérica en 1981, se identificaron en Yucatán los dos primeros casos. Desde entonces, hasta julio del año 2001, oficialmente se han reportado 1367 casos de SIDA en nuestro estado, ubicando a Yucatán en el $4^{\circ}$ lugar nacional por tasa poblacional (14). A partir de esos años, las consecuencias médico-sociales y la dinámica epidemiológica que la infección ha originado, han ido sufriendo transformaciones que permiten conocer mejor su impacto.

El análisis de los casos, permitió identificar tres períodos de la epidemia: 1983-87, 1988-92 y 1993- 


\section{RA Góngora-Biachi, CJ Castro-Sansores, P González-Martínez y col.}

2001 y completar para el análisis a 1200 pacientes. Mil ciento sesenta y cinco $(97 \%)$ casos correspondieron a sujetos $>14$ años y 35 (3\%) a casos pediátricos. De los sujetos > 14 años, 1044 (90\%) fueron hombres y $121(10 \%)$ mujeres, la relación hombre:mujer global fue de 8.6:1. El promedio de edad fue de 34.7 (15-72) años y el de supervencia fue de 24.1 (1-186) meses. Novecientos diez $(76 \%)$ casos correspondieron a Mérida, 252 $(21 \%)$ a zonas urbanas y $38(3 \%)$ a zonas rurales. La relación hombre:mujer en Mérida fue de 8.3:1, en las zonas urbanas 5.7:1 y en las zonas rurales 8.5:1.

\section{Análisis por período en pacientes > 14 años.}

1983-1987. En 1983 se reportan los dos primeros casos de SIDA. Durante este período se reportan en total 30 casos, el $2.6 \%$ del total acumulado. Veintinueve (97\%) eran de Mérida y sólo uno $(3 \%)$ provenía de un medio urbano. Todos eran del género masculino. Veintisiete $(90 \%)$ tenían preferencias sexuales de tipo homosexual y $3(10 \%)$ de tipo bisexual. Veintisiete (90\%) eran solteros, 2 $(7 \%)$ casados y en uno (3\%) se ignoraba su estado civil. Las patologías más frecuentes al reporte del caso fueron: la candidiasis orofaríngea en 17 (57\%) casos, el síndrome de desgaste (SD) en 17 (57\%) y la infección por virus herpes (estomatitis y/o herpes zoster) en 12 (40\%) casos. En este período 27 (90\%) de los casos reportados ya han fallecido.

1988-1992. Se reportan 237 casos que representan el $20 \%$ del total acumulado en sujetos adultos. Ciento noventa y siete $(83 \%)$ eran de Mérida, $35(15 \%)$ de zonas urbanas y $5(2 \%)$ eran de zonas rurales. Docientos dieciseis $(91 \%)$ eran hombres y $21(9 \%)$ mujeres. La relación hombre mujer en este período fue de 10:1. Ciento noventa y ocho (92\%) hombres se infectan por prácticas homo-bisexuales, trece $(6 \%)$ por prácticas heterosexuales y cinco $(2 \%)$ por transfusión. En este período 13 (62\%) mujeres se infectan por prácticas heterosexuales, cinco (24\%) por transfusión, dos (9\%) por ejercicio de la prostitución y un caso (5\%) por drogadicción intravenosa (DIV). Ciento treinta y ocho (58\%) sujetos eran solteros (todos hombres), 74 (31\%) casados $(57(77 \%)$ hombres y $17(23 \%)$ mujeres), ocho $(3 \%)$ viudos $(6(75 \%)$ hombres y dos $(25 \%)$ mujeres), un divorciado $(0.4 \%)$, una unión libre

\section{Revista Biomédica}

$(0.4 \%)$ y en $15(7 \%)$ (13 (87\%) hombres y dos (13\%) mujeres) se ignoraba su estado civil. Las patologías iniciales más frecuentes fueron: SD en 199 (84\%) casos, candidiasis orofaríngea en 137 (58\%) e infección por virus herpes (estomatitis y/o herpes zoster) en 77 (32\%). En este período 195 (82\%) de los casos reportados ya han fallecido.

1993-2001. Se reportan 898 casos, que representan el $77 \%$ del total acumulado en sujetos > 14 años. Seiscientos sesenta y tres $(74 \%)$ eran de Mérida, 204 (23\%) de zonas urbanas y 31 (3\%) eran de zonas rurales. Setecientos noventa y ocho (89\%) eran hombres y $100(11 \%)$ mujeres. La relación hombre:mujer fue de 8:1. Seiscientos cuarenta y un (71\%) hombres se infectan por prácticas homobisexuales, 145 (16\%) por prácticas heterosexuales, siete $(0.7 \%)$ por transfusión, tres $(0.3 \%)$ por DIV, uno $(0.1 \%)$ por prostitución y en un $(0.1 \%)$ caso se ignora su mecanismo de contagio. Entre las mujeres, $93(93 \%)$ se infectan por prácticas heterosexuales, una $(1 \%)$ por transfusión y seis $(6 \%)$ por ejercicio de la prostitución. Quinientos veinte $(58 \%)$ sujetos eran solteros (502 (96\%) hombres y 18 (4\%) mujeres), 263 (29\%) casados (217 (83\%) hombres y $46(17 \%)$ mujeres), $23(2.5 \%)$ viudos (11 (48\%) hombres y 12 (52\%) mujeres), 39 (4\%) divorciados (33 (85\%) hombres y 6 (15\%) mujeres), $24(3 \%)$ uniones libres (18 (75\%) hombres y 6 (25\%) mujeres) y en $17(2 \%)$ (15 (88\%) hombres y dos (12\%) mujeres) se ignoraba su estado civil. Las patologías más frecuentes fueron: SD en 708 (79\%) casos, candidiasis orofaríngea en $227(25 \%)$ y la NPC en $132(15 \%)$. En este período 516 (57\%) de los casos reportados ya han fallecido.

\section{Casos Pediátricos.}

Treinta y cinco (3\%) casos correspondieron a

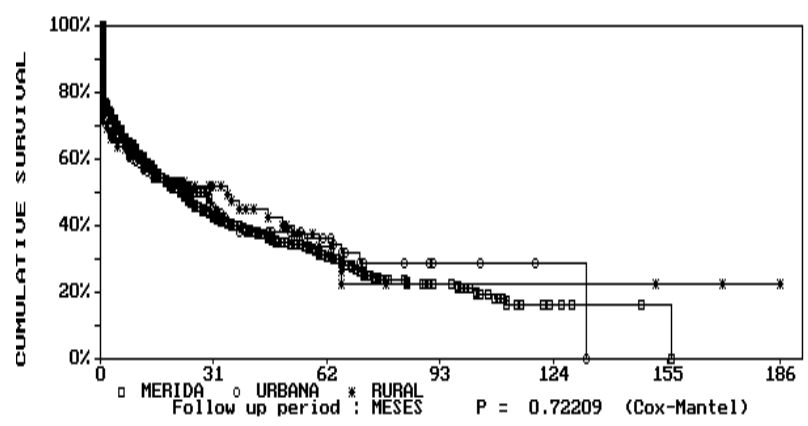

Figura 1.- Supervivencia actuarial por zona geográfica. 


\section{Enfermedades infecciosas endémicas, emergentes y re-emergentes en Yucatán.}

casos pediátricos ( $£ 14$ años). De estos 18 (51\%) fueron hombres y 17 (49\%) mujeres. El promedio de edad fue de 2.8 (1-10) años y el de supervencia fue de 36.3 (1-120) meses. Veintiún (60\%) casos correspondieron a Mérida, $12(34 \%)$ a zonas urbanas y $2(6 \%)$ a zonas rurales. Durante el período $1983-$ 1987 no se observó ningún caso en edad pediátrica en Yucatán.

1988-1992. En este período se reportan 10 casos que representan el $29 \%$ del total acumulado de casos pediátricos. Seis $(60 \%)$ eran del género masculino y $4(40 \%)$ del femenino. En 1988 se reportan las dos primeros casos pediátricos en Yucatán, uno en Mérida y uno en zona urbana. Seis $(60 \%)$ casos se infectaron por transfusión y 4 (40\%) por transmisión perinatal. Siete $(70 \%)$ casos eran de Mérida, y tres $(30 \%)$ de zonas urbana no hubo casos en las zonas rurales. Las patologías iniciales más frecuentes fueron: SD en $8(80 \%)$ casos, candidiasis orofaríngea en $5(50 \%)$, NPC en $3(30 \%)$, infección por virus herpes (estomatitis y/o herpes zoster) en $2(20 \%)$ y un caso (10\%) de TB pulmonar. En este período 7 (70\%) de los casos reportados ya han fallecido.

1993-2001. Se reportan 25 casos que representan el $71 \%$ del total acumulado de casos pediátricos. Doce $(48 \%)$ eran del género masculino y $13(52 \%)$ del femenino. Un (4\%) caso se infectó por transfusión y $24(96 \%)$ por transmisión perinatal. Catorce $(56 \%)$ casos eran de Mérida, nueve (36\%) de zonas urbana y dos $(8 \%)$ eran de zonas rurales. Las patologías iniciales más frecuentes fueron: SD en $22(88 \%)$ casos, candidiasis orofaríngea en 6 (24\%), NPC en 4 (16\%),y tres casos (12\%) de TB pulmonar. En este período $13(52 \%)$ de los casos reportados ya han fallecido.

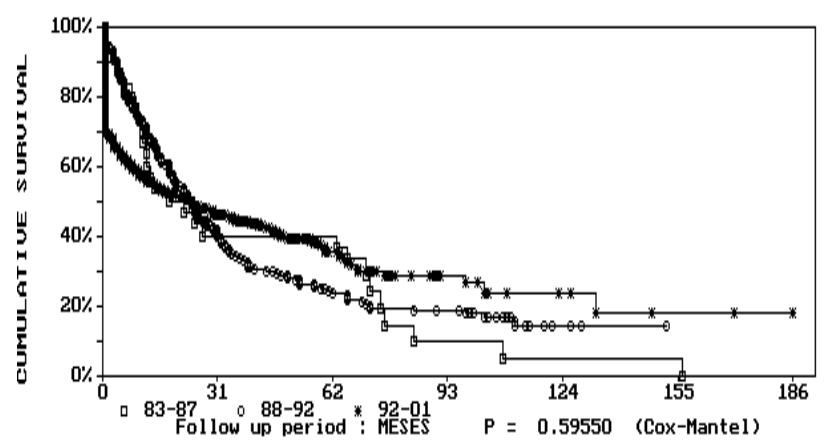

Figura 2.- Supervivencia actuarial por período de notificación.
El patrón inicial de transmisión homo-bisexual, aunque ha permanecido como el predominante en nuestra región ha mostrado un incremento al transcurrir del tiempo, ya que, de no haber casos de transmisión heterosexual en el grupo de hombres en el período 83-87, en el último período el porcentaje de casos fue del 16\%. De igual forma entre las mujeres, el número de casos se ha incrementado durante los últimos dos períodos. Un reflejo de esto último se observa en la transmisión en la edad pediátrica, en donde el porcentaje de casos de transmisión perinatal en el último período fue del $96 \%$ en comparación al $40 \%$ del período inmediato anterior. Las patologías más frecuentes conservan el mismo patrón -patrón africano (14)- durante todo el período de análisis. La ruralización de la epidemia se dio hasta 5 años después del inicio en Mérida y el número de casos sólo representa el $3 \%$ del total.

El grupo de edad más afectado al igual que en las estadísticas nacionales y mundiales (15) se da en el grupo entre 25-44 años que es donde se observa al $69 \%$ de los casos.

Cuando se comparó la supervivencia a través del modelo actuarial de Kaplan-Meier, no se observó diferencia estadísticamente significativa en relación al período en que se reportó el paciente y la zona geográfica de donde era originario (figuras 1 y 2). Sin embargo cuando se analizó por institución tratante se observó una supervivencia mayor estadísticamente significativa cuando el paciente fue tratado de manera privada que en una institución pública (figura 3).

La epidemia del VIH/SIDA en nuestro estado ha mantenido su crecimiento desde su inició en 1983, necesitamos reforzar aún más nuestras campañas de

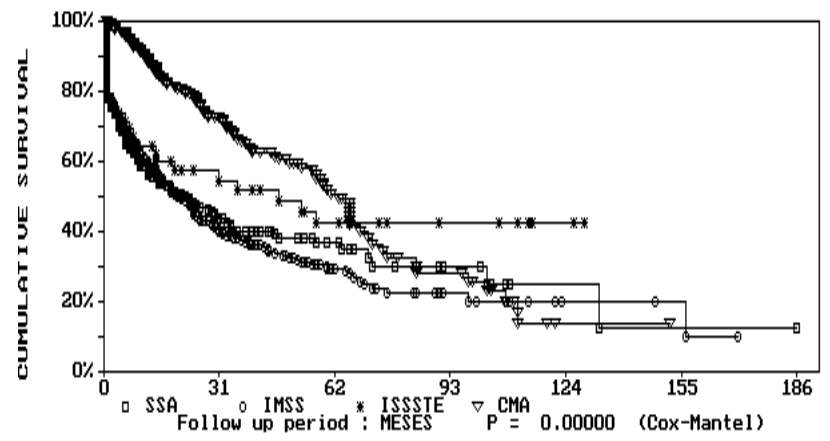

Figura 3.- Supervivencia actuarial por institución notificante.

Vol. 13/No. 2/Abril-Junio, 2002 
RA Góngora-Biachi, CJ Castro-Sansores, P González-Martínez y col.

prevención enfocándola de manera específica a los grupos más vulnerables. Sólo así podremos reducir el número de casos que año con año incrementan nuestra estadística.

\section{EPIDEMIOLOGÍA Y PATOLOGÍAS ASOCIADAS AL VIRUS LINFOTRÓPICO DE CÉLULAS T HUMANAS TIPO II.}

\section{P González-Martínez.}

Los virus linfotrópicos de células $\mathrm{T}$ humanas tipo I y II (HTLV-I y II) son retrovirus biológica y estructuralmente relacionados (17). El HTLV-I es endémico en el suroeste de Japón, la cuenca del caribe y los países del África ecuatorial. El HTLV-II es endémico en etnias de amerindios, en drogadictos intravenosos (DIV) de Estados Unidos y Europa y en politransfundidos (18). En Yucatán, México el HTLV-II es un virus endémico de baja prevalencia $(0.3 \%-0.8 \%)$ (9) y el principal reservorio es el grupo de trabajadoras sexuales (1.6\%-3.5\%) (10); en la etnia maya de Yucatán también se ha identificado el HTLV-II (8). La transmisión del HTLV-I es por vía sexual, DIV y transfusión de sangre y sus derivados. El HTLV-II se transmite por transfusión, DIV, lactancia y vía sexual $(12,19)$.

El HTLV-I es el agente etiológico de la leucemia de células T del adulto (ATL) y de la mielopatía asociada al HTLV-I (HAM); también se ha asociado a iridociclitis, artritis y a otras entidades, aunque con menor frecuencia (20). El HTLV-II no se ha asociado consistentemente con alguna patología.

\section{Leucemia de células $\mathbf{T}$ del adulto.}

Después del aislamiento y caracterización del HTLV-I en 1980, los estudios seroepidemiológicos y moleculares demostraron la asociación causal de este virus con la ATL El largo tiempo de latencia después de la seroconversión permite la continua replicación del HTLV-I y la infección de células T blanco, eventos necesarios para la leucemia-génesis. Los estudios clínicos de Japón han podido identificar tres patrones clínicos: ATL aguda/linfoma, crónica y larvada. Los principales hallazgos clínicos son adenomegalia, hepatomegalia, esplenomeglia, lesiones dérmicas e hipercalcemia;. La cuenta de leucocitos varía desde cifras normales hasta 500,000/ $\mu \mathrm{L}$; en casi todos se encuentran células leucémicas, del tipo de linfocitos $\mathrm{T} \mathrm{CD}^{+}$. La supervivencia de la variedad aguda/linfoma en promedio es de dos semanas a un año; las formas crónicas y larvadas evolucionan a la forma aguda después de 8 a 20 años (20).

\section{Mielopatía asociada al HTLV-I.}

Esta enfermedad se asocia más a la transmisión por transfusión sanguínea y se caracteriza por una mielopatía espástica, progresiva, con afectación de cordones posteriores y con menor grado el sistema sensorial. Existen trastornos en la micción, defecación, marcha y equilibrio. En el líquido cefalorraquídeo se encuentran linfocitos infectados con HTLV-I (21).

\section{Virus linfotrópico de células T humanas tipo II.}

El HTLV-II aunque no se ha asociado con alguna patología ha sido relacionado con enfermedades de diversos tipos: neurológicas, hematológicas, dermatológicas, síndrome de la fatiga crónica, enfermedades endocrinas y la infección por el virus de la inmunodeficiencia humana (VIH).

Neurológicas.- Se ha descrito un síndrome similar a la HAM (mielopatía crónica progresiva, paraparesia espástica, ataxia, disfunción vesical, trastornos sensoriales). En pacientes infectados por el VIH y que presentaron neuropatía sensorial, se detectó una alta prevalencia de Ac-HTLV-II. Por técnicas de reacción en cadena de la polimerasa se encontraron secuencias provirales en un nervio femoral (22).

Hematológicas.- Aunque originalmente el HTLV-II se aisló de un caso de leucemia de células peludas, actualmente no se considera asociado a esta patología. Adicionalmente se han reportado al menos 3 casos de leucemia linfocítica de linfocitos grandes granulares asociada al HTLV-II y en casos aislados de leucemia linfocitica crónica atípica y prolinfocítica.. En Yucatán, México se han documentados dos casos similares a la ATL asociados al HTLV-II (23).

Dermatológicas.- Kaplan y col. han reportado dos casos de dermatitis infiltrativa, linfoadenopatía dermatopática y eosinofilia y un caso de ictiosis en

\section{Revista Biomédica}




\section{Enfermedades infecciosas endémicas, emergentes y re-emergentes en Yucatán.}

pacientes coinfectados por VIH y HTLV-II (24).

Síndrome de fatiga crónica (SFC).-Un reporte de 30 casos con el SFC demostró que 15 de ellos $(50 \%)$ tenían Ac-HTLV-II, diferente del grupo control $(0 / 10)(25)$.

Enfermedades endocrinas.- Yokoi y col. detectaron elementos provirales de HTLV-II en 52\% de pacientes con tiroiditis de Hashimoto y en $12 \%$ de pacientes con enfermedad de Graves, contra el $1 \%$ de personas sana; sin embargo ninguno de estos pacientes tenía Ac-HTLV-II (26).

Coinfección del HTLV-II y el VIH.- En forma diferente a la coinfección con el HTLV-I, el HTLVII parece no tener efecto en la evolución del SIDA, medido en función de la evolución de la enfermedad y el desarrollo de complicaciones graves, principalmente infecciones oportunistas y neoplasias malignas, aunque se han reportados casos aislados de linfoma cutáneo asociado a HTLV-II en un paciente coinfectado por VIH (27). En cinco pacientes yucatecos con infección por el HTLV-II y el VIH-1, seguidos de dos a cuatro años, el curso clínico de la infección por VIH no se ha modificado en forma desfavorable (Góngora-Biachi RA, datos no publicados).

En conclusión se considera que:

a) El impacto biológico del HTLV-II todavía no está definido.

b) El reporte de varios casos y el estudio de algunas series asocian más frecuentemente al HTLVII con patologías tipo HAM.

c) $\mathrm{Su}$ papel en el desarrollo de neoplasias oncohematológicas parece infrecuente.

d) La coinfección del VIH y el HTLV-II no parece influir en la progresión de la enfermedad por VIH/SIDA

e) La participación del HTLV-II en procesos dermatológicos, endocrinológicos y el síndrome de fatiga crónica requiere de mayores evidencias.

f) Aún es necesario definir la patogenicidad del HTLV-II a través de estudios de cohorte, de biología y epidemiología molecular.

\section{HTLV-II en Yucatán.}

Los estudios cooperativos del Laboratorio de Hematología del Centro de Investigaciones Regionales de la Universidad Autónoma de Yucatán con la Universidad de Kumamoto Japón y el CDC de Atlanta, Ga., iniciados desde 1990, han permitido definir que en Yucatán el HTLV-II es endémico, con una frecuencia en la población general y donadores del 0.3 al $0.8 \%$. Llama la atención que el grupo con mayor prevalencia de infección, hasta ahora detectado, es el de las sexo-trabajadoras, lo que sugiere la participación de estas mujeres, no drogadictas intravenosas, en la diseminación de la infección por el HTLV-II.

Aunque hasta ahora no tenemos, como en otros sitios, evidencia de asociación causal con alguna enfermedad específica, ¿en nuestra región, está participando el HTLV-II con algún papel patogénico? ¿Con qué patologías se asocia más frecuentemente esta infección y cuál es su impacto en los cursos clínicos de ellas? Debido al largo período de latencia de la infección por este retrovirus humano, es necesario continuar con el programa de seguimiento que permita a mediano o a largo plazo, contestarnos estos cuestionamiento.

\section{IMPACTO EPIDEMIOLÓGICO DEL VIRUS DE INFLUENZA.}

\section{G Ayora-Talavera.}

Influenza es el nombre asignado a una enfermedad respiratoria aguda y febril de importancia global, causada por los tipos A, B y C del virus de influenza. Esta enfermedad se presenta en el hombre en dos formas epidemiológicas: influenza pandémica e influenza Inter-pandémica (28).

Existe una red internacional de vigilancia del virus de influenza, establecida por la Organización Mundial de la Salud desde 1947. Esta red internacional está formada por 110 centros nacionales distribuidos en 80 países (29).

En Yucatán, el programa de vigilancia epidemiológica se inició en 1998 con la participación de cuatro instituciones hospitalarias. Para el año de 1999 y hasta la fecha, la red de vigilancia en el Estado está constituida por 7 unidades centinelas: Hospital O'Horan, ISSSTE, Hospital de Valladolid, Centro de Salud de Progreso, Centro de Salud de Tizimin, Hospital Militar y el IMSS.

Vol. 13/No. 2/Abril-Junio, 2002 


\section{RA Góngora-Biachi, CJ Castro-Sansores, P González-Martínez y col.}

Como resultado del programa de vigilancia epidemiológica, hasta septiembre del 2001 se recibieron un total de 698 exudados faríngeos de pacientes con un cuadro clínico semejante al de influenza. Para el período 1998-1999 de un total de 283 exudados, 25 (8.8\%) fueron positivos al virus de influenza. Para los períodos 1999-2000 y 20002001 se colectaron 204 y 211 exudados faríngeos respectivamente con $12(5.8 \%)$ y $15(7 \%)$ muestras positivas al virus de influenza respectivamente. Los virus aislados fueron caracterizados como influenza A subtipo H3N2.

Estos tres años de vigilancia epidemiológica han demostrado que en Yucatán el virus de influenza y la enfermedad se han presentado como casos aislados. Se ha observado que durante los meses de diciembre, enero y febrero ocurre un incremento del numero de casos positivos, y este incremento se vuelve a dar durante los meses de mayo, junio y julio. En Yucatán, como lo evidenciaron estos resultados, es difícil establecer un período estacional, tal y como se observa en los países templados que presentan un período epidémico (Octubre-Marzo). Se ha reportado que en los países tropicales y subtropicales no existe una estacionalidad del virus de influenza (30).

Con respecto a los grupos de edad el análisis de los resultados del programa de vigilancia muestran, que los grupos de edad se han visto afectados de la siguiente manera: $<5$ años 8 casos positivos de 196 (4.0\%), 5-14 años 10 positivos de 118 (8.4\%), 15-24 años 9 positivos de 98 (9.1\%), 25-44 años 14 positivos de 163 (8.5\%), 45-64 años con 4 positivos de $64(6.25 \%)$ y $>65$ años con 4 positivos de $59(6.7 \%)$.

Entre los signos y síntomas más frecuentes en los casos positivos se encuentran la tos (97\%), seguido de la fiebre $(71.4 \%)$, el malestar general $(48.9 \%)$ y la cefalea $(42.8 \%)$.

La obtención de estos resultados ha sido a través del uso de técnicas de laboratorio rápidas como la inmunofluorescencia indirecta (IFI) y el cultivo celular para la identificación de las cepas de virus circulantes. El cultivo en células o embriones de pollo es un requisito para caracterizar las cepas que formarán la vacuna de influenza anual. Existen otros métodos más sensibles y específicos para el diagnóstico del virus de influenza como la reacción en cadena de la polimerasa (PCR).
El virus de influenza por su habilidad a intercambiar material genético es capaz de emerger o re-emerger como un virus nuevo con el potencial de dispersarse rápidamente a poblaciones susceptibles y causar epidemias y/o pandemias mundiales.

Sin embargo, para que una epidemia o pandemia ocurra, es necesario que en los humanos aparezca un virus nuevo, que sea hábil y capaz de causar enfermedad en los humanos y que exista una población que sea susceptible a este virus nuevo (31).

Para poder prevenir la ocurrencia de estos hechos es necesario llevar a cabo una vigilancia epidemiológica continua que este diseñada para identificar el inicio de la actividad de la influenza en una población y caracterizar a los virus, conocer la extensión de la morbilidad y mortalidad ocasionada por el virus circulante y poder predecir los tipos de virus y la extensión de la enfermedad.

En conclusión, es necesario poseer un plan pandémico que permita desarrollar estrategias y tácticas para responder al problema. Es muy necesario el intercambio de información oportuna que permita predecir el riesgo pandémico.

\section{LA HEPATITIS C: SU IMPACTO EN YUCATÁN.}

\section{RA Góngora-Biachi.}

El virus de la hepatitis C (VHC) es miembro de la familia flaviviridae, identificado en 1989 (32). Se reconoce 6 genotipos diferentes de VHC (33). Se estima que 150 millones de personas en el mundo están infectadas por el VHC (34).

Se han podido identificar algunos factores asociados a la transmisión del VHC (35) (cuadro IV). Otros factores que se asocian a la transmisión del virus de la hepatitis $B$ no se han relacionado consistentemente con la transmisión de la hepatitis C. Entre estos están: servicio militar, exposición en procedimientos médicos, tatuajes, acupuntura orificios n orejas y viajes en el extranjero. En los Estados Unidos de Norteamérica el 10\% de los casos no se identifica alguna causa (35).

En Yucatán, la prevalencia de infección, tanto en población urbana y como en la rural, es de $1.3 \%$

\section{Revista Biomédica}


Enfermedades infecciosas endémicas, emergentes y re-emergentes en Yucatán.

Cuadro IV

Factores asociados y no asociados a la infección del Virus de la Hepatitis C.

\begin{tabular}{ll}
\hline FACTORES ASOCIADOS & FACTORES NO ASOCIADOS \\
\hline Transfusión sanguínea & Servicio militar \\
& \\
Uso de drogas intravenosas & Exposición a procedimientos médicos \\
Trabajo en hospital o laboratorio clínico & Tatuajes \\
Historia de hepatitis en la pareja sexual & Acupuntura \\
Historia de hepatitis en cohabitantes de la & Orificios en orejas \\
misma casa & Viajes al extranjero \\
Exposición a múltiples parejas sexuales & \\
Nivel socio-económico bajo & \\
\hline
\end{tabular}

(36). En más del 95\% no se identifica un cuadro de hepatitis aguda. El $11 \%$ de los seropositivos existe el antecedente de transfusión sanguínea. El 14\% de los cónyuges de los seropositivos tienen anticuerpos contra el VHC.(Ac-VHC); En los seropostivos el antecedente de transfusión se detecta en el $11 \%$ de los casos (36).

Estudios realizados por nuestro grupo han identificado algunos factores que se asocian a la seropositividad de VHC y se describen en el cuadro IV.

Por otro lado la prevalencia de Ac-VHC en diferentes grupos de población se describe en el cuadro VI. Puede observarse que la mayor prevalencia de infección por VCH está en los grupos de cirrosis hepática (32\%), hepatocarcinoma (28\%) y en los poli transfundidos (12.5\%).

El $80 \%$ de las personas que se infectan con el VHC progresan a enfermedad crónica y el curso posterior de esta condición es uno o más de estos siete eventos: recuperación completa, con viremia sin evidencia bioquímica de daño hepático, hepatitis crónica, fibrosis histológica y cirrosis, cirrosis estable por largo tiempo, cirrosis progresiva y hepatocarcinoma (37).

\section{Cuadro V}

Factores asociados a infección por el Virus de la Hepatitis C, identificados en Yucatán, México.

\begin{tabular}{ll}
\hline FACTORES & RR \\
\hline Cirrosis hepática & 4.28 \\
Casa con tierra de piso & 3.3 \\
Vivir en medio rural & 1.85 \\
Transfusiones sanguíneas & 1.36 \\
Comer fuera de la casa & 1.3 \\
Relaciones sexuales extra-conyugales & 1.25 \\
\hline
\end{tabular}

\section{Cuadro VI}

Prevalencia de anticuerpos contra el Virus de la Hepatitis $\mathrm{C}$ en diferentes grupos de población, en Yucatán, México.

\begin{tabular}{lccc}
\hline GRUPO & POSITIVO/TOTAL & $\%$ & P* \\
\hline Personas sanas/donadores & $29 / 2313$ & 1.25 & \\
Pacientes Oncológicos/Hematológicos & $9 / 267$ & 3.4 & 0.014 \\
Otros pacientes & $2 / 81$ & 2.5 & $\mathrm{NS}$ \\
Prostitutas & $4 / 127$ & 3.1 & $\mathrm{NS}$ \\
Politrasnfundidos & $13 / 104$ & 12.5 & 0.0001 \\
Cirrosis hepática & $49 / 153$ & 32.0 & 0.0001 \\
Hepatocarcinoma & $4 / 14$ & 28.0 & 0.0003 \\
\hline
\end{tabular}

* valor de p al comparar los diferentes grupos con el grupo de personas sanas/donadores. 


\section{RA Góngora-Biachi, CJ Castro-Sansores, P González-Martínez y col.}

Se estima que del $6 \%$ al $26 \%$ de las personas con infección crónica desarrollan cirrosis en un lapso de 18 a 25 años. En estos pacientes el hepatocarcinoma ocurre exclusivamente asociado a cirrosis (riesgo de 3 a $10 \%$ por año) (38). En Yucatán, si consideramos la prevalencia de Ac-VHC de $1.3 \%$ en mayores de 18 años, entonces aproximadamente 13,107 personas estarían infectadas por el VHC y de éstas 10,486 desarrollarán infección crónica, de los cuales entre 629 a 2,726 desarrollarán cirrosis hepática.

Algunos de los factores que se asocian a cirrosis hepática por VHC están presentes en Yucatán: muchos casos con infección mayor de 20 años, gente que se infectó a edades menores de 40 años, el consumo crónico de alcohol recientemente la epidemia de VIH. Por otro lado, queda por definir la incidencia de manifestaciones extra-hepáticas de la infección de VHC en Yucatán, como lo son la crioglobulinemia esencia mixta, el linfoma, el linfoma hepático, glomerulonefritis, la porfiria cutánea tarda y la diabetes mellitus.

Los avances recientes y el éxito del tratamiento con peginterferón alfa-2a, tanto en los pacientes con hepatitis crónica como en los pacientes con cirrosis (39), así como en la prevención del hepatocarcinoma asociado (40), justifican la detección temprana de este virus en pacientes con hepatopatía crónica y en patologías potencialmente asociadas.

\section{EL VIRUS DEL DEL NILO OCCIDENTAL: UNA ENFERMEDAD DE EMERGENCIA POTENCIAL.}

\section{MA Loroño-Pino.}

Un brote de meningo-encefalitis asociado con debilidad muscular en humanos fue reportado en la ciudad de Nueva York a principios de Agosto de 1999, al mismo tiempo que ocurrían miles de muertes de dos especies de cuervos (Corvus brachyrhynchos y C. ossifragus). Inicialmente el brote se atribuyó al virus de la encefalitis de San Luis (ESL). La encefalitis de San Luis es una enfermedad viral transmitida por mosquitos, enzoótica en los Estados Unidos de Norte América, sin embargo normalmente no es causante de mortandad entre sus huéspedes Revista Biomédica reservorios aviares. El brote duró dos meses con un total de 62 personas con encefalitis incluyendo 7 fallecidos (41). Estudios virológicos posteriores indicaron que el virus del Nilo Occidental (VNO) fue el agente etiológico de este brote. Pruebas de aislamiento viral o serológicas confirmaron la infección por el VNO en humanos, en varias especies de vertebrados y en diferentes especies de mosquitos. Los análisis filogenéticos basados en la secuencia de nucleótidos del VNO aislados de varios cuervos y un flamenco del zoológico de Bronx claramente mostraron su similitud con virus circulantes en el Medio Oriente en 1998 (42).

El VNO es enzoótico en Africa, Europa, Asia y Medio Oriente. Los típicos reservorios incluyen una amplia variedad de pájaros y los vectores principales son mosquitos del género Culex. La mayoría de las infecciones en humanos son subclínicas, estimándose que se presentan manifestaciones clínicas en aproximadamente 1 de cada 100 infecciones. La tasa de fatalidad está entre el 3\% al 15\%, siendo mayor entre los ancianos (43). Los signos y síntomas varían de fiebre, dolor de cabeza y eritema maculo-papular o con erupción morbiliforme a meningo-encefalitis (44).

En los últimos dos años, este virus se ha ido diseminando rápidamente hacia el sur y hacia el oeste de los Estados Unidos de América, pese al enorme esfuerzo de organización e investigación realizado por las instituciones de salud humana y veterinaria, geográfica, de agricultura y defensa de ese país. Un número cada vez mayor de aves, humanos, mosquitos, caballos y otras especies de mamíferos continúan reportándose como positivos (45).

Debido a la inminente llegada de este virus a nuestro país y al interés del laboratorio de Arbovirología de estudiar los arbovirus de la región, estamos realizando un trabajo de investigación en colaboración con investigadores del Arthropod Borne and Infectious Diseases Laboratory del Departamento de Microbiología de Colorado State University para detectar la llegada del virus a la Península de Yucatán. Este proyecto está financiado actualmente por The National Institutes of Health y el Center for Disease Control and Prevention. En este estudio se capturan aves de tres regiones del estado de Yucatán (el Rancho Hobonil en Tzucacab, la Reserva ecológica de Cuxtal y la Reserva de la Ría 


\section{Enfermedades infecciosas endémicas, emergentes y re-emergentes en Yucatán.}

Celestún). Estas aves se clasifican, se les toma una pequeña muestra de sangre y se liberan. Una vez que este virus sea detectado circulando en la región, se informará a las autoridades para que tomen las medidas pertinentes tendientes a combatir y prevenir la proliferación de los principales vectores, los mosquitos Culex, así como para la realización de programas para la educación del público. Los médicos deberán mantener una vigilancia para la detección de casos de encefalitis y reportarlo a las autoridades de salud. La comunidad de médicos veterinarios juega también un papel muy importante en la vigilancia de este virus.

\section{DENGUE EN YUCATÁN: SU EVOLUCIÓN Y PERSPECTIVA EPIDEMIOLÓGICA.}

\section{JA Farfán-Ale.}

Los virus del dengue contienen un genoma de ácido ribonucleico (ARN) de una sola hebra que consta de aproximadamente 11,000 nucleótidos. Este genoma codifica para una sola poliproteína la cual es procesada para dar 10 proteínas, las cuales son: cápside $(\mathrm{C})$, pre-membrana (prM), envoltura (E) y las proteínas no estructurales (NS1, NS2A, NS2B, NS3, NS4A, NS4B y NS5) (46-47). Los virus del dengue (serotipos 1-4) son transmitidos a los humanos por los mosquitos del genero Aedes (Ae.), siendo el Ae. aegypti el principal vector. Aproximadamente 2,500 millones de personas viven en áreas en riesgo para la transmisión epidémica del dengue (48). Dos formas clínicas de la infección por virus del dengue han sido reconocidas: la fiebre por dengue (FD) y la fiebre hemorrágica por dengue (FHD). En el hemisferio Occidental, la transmisión de los virus del dengue ha aumentado dramáticamente en los últimos 25 anos (49). En la actualidad circulan en el Continente Americano los cuatro serotipos del virus del dengue. La introducción de los nuevos serotipos de dengue, el decline en el control de los mosquitos, el aumento de los viajes por avión y la urbanización de las ciudades, han contribuido a los dramáticos cambios en la epidemiología del dengue en el Continente Americano (48).

En el estado de Yucatán el dengue ha sido prevalente desde 1979, habiéndose registrado las mayores epidemias en 1979, 1980, 1984, 1991, 1994 , 1997 y 2001 (50, 51). Los cuatro serotipos de los virus del dengue han sido detectados en la región y aunque la mayoría de los casos han sido clasificados como fiebre por dengue, en diferentes épocas se han registrado casos con manifestaciones hemorrágicas, algunos de los cuales han resultado en fatalidades (50). El mosquito Aedes aegypti ha sido el único vector encontrado en todas las epidemias. En 1994 se registro un incremento en el numero de casos de dengue comparado con los anos anteriores. Un total de 531 casos fueron confirmados por laboratorio. Esta epidemia fue causada por el serotipo 1 del virus dengue. Este serotipo había circulado en anos previos en la Península de Yucatán, lo que hace considerar la posibilidad de que una variante del mismo serotipo fue la que causo la epidemia.

Los virus con genoma de ARN son los parásitos celulares más ampliamente distribuidos en la naturaleza. Ellos se pueden encontrar intracelularmente en casi todas las formas de vida. Se ha estimado que más del $70 \%$ de todos los virus que infectan a diversos organismos tienen genoma de ARN. Estos virus han sido estudiados extensamente debido a que son los responsables de una variedad de enfermedades que afectan a los hombres, animales y plantas y por tanto son importantes médica y económicamente. Algunas de las enfermedades causadas por estos virus de ARN son: SIDA, poliomielitis, algunas encefalitis, rabia, influenza y dengue (52-54).

No se han encontrado exonucleasas con prueba de lectura en sistemas de replicación de ARN, así que los niveles de error por genoma están entre $1 \times 10$ ${ }^{3}$ a $1 \times 10^{-4}$ por ciclo de replicación (10). La fuente primaria para la variación en los virus de ARN es la mutación puntual (55-57).

Los genomas de los virus de ARN tienen un promedio de $10 \mathrm{~Kb}$. Un virus con este tamaño de genoma y con una substitución de bases de $1 \times 10^{-4}$ tendrá al menos una mutación en la mayoría de sus ciclos de replicación (55-57). Dado que los virus del dengue tienen aproximadamente $10^{4}$ nucleótidos, una mutación puede ocurrir por ciclo de replicación.

Recientemente se ha identificado evidencia de recombinación ene algunas cepas de virus dengue 2 (58). Por otra parte, en el Laboratorio de Arbovirología hemos analizado la variabilidad de los

Vol. 13/No. 2/Abril-Junio, 2002 


\section{RA Góngora-Biachi, CJ Castro-Sansores, P González-Martínez y col.}

virus del dengue en cada uno de 4 serotipos, usando RT-PCR y SSCP como técnicas de rastreo. Como marcador de la variabilidad genotípica de los virus usamos el gene que codifica para el precursor de la proteína $\mathrm{M}$ ( $\mathrm{prM}$ ) identificamos variantes virales en los cuatro serotipos de los virus del dengue aislados en la península de Yucatán (59).Los datos propuestos en párrafos anteriores nos permiten considerar la posibilidad que los cambios en el genoma de los virus del dengue, que ocurren como resultado del proceso evolutivo de los mismos, pudieran resultar en cepas con mayor capacidad para ser transmitidas o de mayor virulencia.

\section{REFERENCIAS.}

1.- Lederberg J. Emerging Infection: an evolutionary perspective. Emerg Infect Dis 1998; 4:366-71.

2.- Góngora-Biachi RA, Castro-Sansores C, PérezCarrillo H, González-Losa MR, Rodríguez-Angulo E, Farfán-Ale JA, et al. Enfermedades emergentes y reemergentes en Yucatán a finales del siglo XX. Rev Biomed 1997; 8:247-65.

3.- Fauci AS. New and reemerging diseases: the importance of biomedical research. Emerg Infect Dis 1998; 4:374-8.

4.- Morse SS. Factors in the emergence of infectious diseases. Emerg Infect Dis 1995; 1:1-12.

5.- Góngora-Biachi RA, González-Martínez P. La dinámica epidemiológica de la infección por el VIH-1 en Yucatán (1983-1989). Rev Biomed 1990; 1:53-60. 6.- Góngora-Biachi RA, González-Martínez P. Anticuerpos contra el virus de Inmunodeficiencia humana (VIH) en una población de prostitutas de Mérida, Yucatán, México. Rev Invest Clin 1987;39:3056.

7.- Góngora-Biachi RA, Valadez-González N, CastroSansores C, Guerrero-Flore A, Vera-Gamboa L. V Simposio de Actualización: SIDA 2000. Rev Biomed 2001; 12:47-62.

8.- Góngora-Biachi RA, Lal RB, Rudolph DL, CastroSansores C, González-Martínez P, Pavía-Ruz N. Low prevalence of HTLV-II in mayan indians in the Yucatán Peninsula, México. Arch Med Res 1997; 28:555-8.
9.- Góngora-Biachi RA, González-Martínez P, Puerto FI, Sosa-Muñoz J, Duarte-Zapata L, Bastarrachea-Ortiz $\mathrm{J}$, et al. A low prevalence of HTLV-I/II infection among eight population groups from Mérida, Yucatan, Mexico. J Acq Immun Def Synd 1992; 5:104-6.

10.- Gongora-Biachi RA, Gonzalez-Martinez P, CastroSansores C, Pavia-Ruz, Rudolph DL, Lal RB. Human T Lymphotropic Virus type II (HTLV-II) infection among female prostitutes in Yucatan Mexico. Am J Med Sci 1993; 306:207-11.

11.- González-Martínez P, Castro-Sansores C, VivasRosel ML, Góngora-Biachi RA. Infección por el virus linfotrópico de células T humanas tipo I/II en pacientes poli transfundidos en el estado de Yucatán, México. Sangre 1994; 39:45-8.

12.- Lal RB, Góngora-Biachi RA, Pardi D, Swizer WM, Goldman I, Lal AA. Evidence for mother-to-child transmission of Human T Lymphotropic Virus type II. J Infect Dis 1993; 168:586-91.

13.- Hayes CG. West Nile Virus: Uganda, 1937, to New York City, 1999. Ann N Y Acad Scien 2001; 951: 2537.

14.- Secretaría de Salud. Estadísticas. http:// www.ssa.gob.mx.

15.- N'galy B, Ryder RW. Epidemiology of HIV infection in Africa. J Adquir Inmune Defic Syndr 1988;1:551-8.

16.-Report on the global HIV/AIDS epidemic-June 2001 http://www.unaids.org/epidemic_update/report_dec01/ index.html.

17.- Hjelle B. Human T-cell leukemia/lymphoma viruses: Life cycle, pathogenicity, epidemiology and diagnosis. Arch Pathol Lab Med 1991; 115: 440-50.

18.- Manns A, Blattner WA. The epidemiology of human T-cell lymphotropic virus type I and type II: etiologic role in human disease. Transfusion 1991; 31: 67-75.

19.- Góngora-Biachi RA, González-Martínez P, Puerto FI, Pavía-Ruz N, Baeza-Bacab M. Primer caso en México de infección por el virus linfotrópico de células $T$ humanas asociado a transfusión sanguínea en una niña. Rev Invest Clin 1991; 43:399-400.

20.- Yamaguchi K, Kiyokawa T, Futami G, Ishii T, Takatsuki K. Patogénesis of adult T-cell leukemia from

\section{Revista Biomédica}




\section{Enfermedades infecciosas endémicas, emergentes y re-emergentes en Yucatán.}

clinical pathology features. In: Blattner W, ed. Human Retrovirology: HTLV. New York. Raven Press; 1990. p. 163-71.

21.- Osame M, Usuku K, Izumo S, Ijichi N, Amitani H, Igata A, et al. HTLV-I associated myelopathy, a new clinical entity. Lancet 1986: 1:1031-2.

22.- Zehender G, De Maddalena C, Osio M, Cavalli B, Parravicini C, Moroni $\mathrm{M}$, et al. High prevalence of human $\mathrm{T}$ cell lymphotropic virus type II infection in patients affected by human immunodeficiency virus type 1 -associated predominantly sensory polyneuropathy. .J Infect Dis 1995; 172: 1595-8.

23.- Hjelle B, Mills R, Swenson S, Mertz G, Key C, Allen $\mathrm{S}$. Incidence of hairy cell leukaemia, mycosis fungoide and chronic lymphocytic leukaemia in first know HTLVII-endemic population. J Infect Dis 1991; 163:435-40.

24.- Kaplan MH, Sadick NS, McNutt NS, Talmor M, Coronesi M, Hall WW. Acquired ichthyosis in concomitant HIV-1 and HTLV-II infection: a new association with intravenous drug abuse. J Am Acad Dermatol 1993; 29:701-8.

25.- Defreitas E, Hilliard B, Cheney P, Bell DS, Kiggundu E, Sankey D, et al. Retroviral sequences related to human T-Lymphotropic virus type II in patients with chronic fatigue immune dysfunciones syndrome. Proc Natl Acad Sci USA 1991; 88:2922-6.

26.- Yokoi K, Kawai H, Akaike M, Mine H, Saito S. Presence of human T-lymphotropic virus type II-related genes in DNA of peripheral leukocytes from patients with autoimmune thyroid diseases. J Med Virol. 1995; 45:392-8.

27.- Poiesz B, Dube D, Dube S, Love J, Papsidero L, Uner A, et al. HTLV-II-associated cutaneous T-cell lymphoma in a patient with HIV-1 infection. $\mathrm{N}$ Engl J Med 2000; 342:930-6.

28.- Stamboulian D, Bonvehi PE, Nacinovich FM, Cox NJ. Influenza. Infect Dis Clin NA 2000; 14:141-66.

29.- Cox N., Subbarao K. Global epidemiology of influenza: Past and present. Ann Rev Med 2000; pp 40718.

30.- Nguyen Van Tam JS. Epidemiology of influenza. En: Nicholson KG., Webster RG., Hay AJ, editor. Textbook of influenza. . Oxford :Blackwell Science Ltd.;
1998. p.181-206.

31.- Leese J, Tamblyn SE. Pandemic planning. En: Nicholson KG., Webster RG., Hay AJ, editors. Textbook of influenza. Oxford:Blackwell Science Ltd ;1998. p. 551-9.

32.- Choo QL, Kuo G, Weiner AJ, Overby LR, Bradly DW, Hougton M. Isolation of a DNA clone derived from a blood borne non-A non-B viral hepatitis genome. Science 1989; 244: 359-362.

33.- Pozzato G, Kaneko S, Moretti M, Croce Ls, Franzin F, Unoura M. Different genotypes of hepatitis C virus are associated with different severity of chronic liver disease. J Med Virol 1994; 43: 291-296.

34.- Amarapurkar D. Natural history of hepatitis $C$ virus infection. J Gastroenterol Hepatol 2000; 15: S105-S110.

35.- Liang TJ, Rehermann B, Seeff LB, Hoofnagle JH. Pathogenesis, natural history, treatment, and prevention of Hepatitis C. Ann Intern Med 2000; 132: 296-305.

36.- Góngora-Biachi RA, González-Martínez P, Puerto FI, Yamaguchi K, Nishimura Y, Takatsuky K. Antibodies to hepatitis $\mathrm{C}$ virus in people from Yucatán, México. Rev Invest Clin 1992; 44: 284.

37.- Alberti A, Chemello L, Benvegnù. Natural history of hepatitis C. J Hepatol 1999; 31: (Supp.1) 17-24.

38.- Colombo M. Natural history and pathogenesis of hepatitis $\mathrm{C}$ virus related hepatocellular carcinoma. J Hepatol 1999; 31: (Supp.1) 25-30.

39.- Heathcote EJ, Shiffman ML, Cooksley GE, Dusheiko GM, Lee SS, Balart L, Reindollar R, Reddy RK, Wright TL, Lin A, Hoffman J, De Pamphilis J. Peginterferon alfa-2a in patients with chronic hepatitis C and cirrhosis. N Engl J Med 2001; 343: 1673-80.

40.- Baffis V, Shrier I, Sherker AH, Szilagyi A. Use of interferon for prevention of hepatocellular carcinoma in cirrhotic patients with hepatitis $\mathrm{B}$ or $\mathrm{C}$ virus infection. Ann Intern Med 1999; 131: 696-701.

41.- Craven R and Roehrig JT. West Nile Virus. JAMA 2001; 28:651-3.

42.- Lanciotti RS, Roehrig JT, Deubel V, Smith J, Parker $\mathrm{M}$, Steele K, et al. Origin of the West Nile Virus responsible for an outbreak of encephalitis in the

Vol. 13/No. 2/Abril-Junio, 2002 


\section{RA Góngora-Biachi, CJ Castro-Sansores, P González-Martínez y col.}

Northeastern United States. Science 1999; 286:2333-7. 43.- http://www.cdc.gov/ncidod/dvbid/westnile/q\&a.htm

44.- Nash D, Mostashari F, Fine A, Miller J, O’Leary $\mathrm{D}$, Murray $\mathrm{K}$, et al. The outbreak of West Nile Virus infection in the New York city area in 1999. N Engl J Med 2001; 344:1807-14.

45.- Centers for Disease Control and Prevention. Epidemic/Epizootic West Nile Virus in the United States: Revised Guidelines for surveillance, prevention, and control. U.S. Dept of Health and Human Services, CDC Fort Collins, Colorado, 2001.

46.- Chambers TJ, Hahn CS, Galler R, Rice CM. Flavivirus genome organization, expression, and replication. Annu Rev Microbiol , 1990; 44: 649-88.

47.- Henchal EA, Putnak JR. The dengue viruses. Clin Microbiol Rev 1990; 3:1376-96.

48.- Gubler DJ, Clark GG. Dengue/dengue hemorrhagic fever: The emergence of a global problem. Emerg Infect Dis $1995 ; 1: 55-7$.

49.- Monath TP. Dengue: the risk to developed and developing countries. Proc Natl Acad Sci USA 1994; 91:2395-400.

50.- Farfán-Ale JA, Loroño-Pino MA. Incidencia de infección por virus dengue en niños de 8 a 14 anos de edad radicados en las áreas urbana y rural del municipio de Mérida, Yucatán. Bol Med Hosp Infant Mex 1991; 48:780-4.

51. Loroño- Pino MA, Farfán-Ale JA, Rosado-Paredes EP, Kuno G, Gubler DJ. Epidemic dengue 4 in the Yucatan, Mexico, 1984. Rev Inst Med Trop Sao Paulo 1993; 35:449-55.

52. Holland J, Spindler K, Horodysky F, Grabav E, Nichol S, Vanderpol S. Rapid evolution of RNA genomes. Science 1982; 215: 735-44.

53. Holland J. (1984) Continuum of change in RNA virus genomes. In Notkins AL, Oldstone MBA, Editors. "Concepts in Viral Pathogenesis". New York:SpringerVerlag; 1984. pp. 137-43.
54. Steinhauer DA, Holland JJ. Rapid evolution of RNA viruses. Annu. Rev Microbiol 1987; 41: 409-33.

55. Steinhauer D A, Domingo E, Holland J J. Lack of evidence for proofreading mechanisms associated with an RNA virus polymerase. Gene 1992;122: 281-8.

56. Smith D B, Inglis S C. The mutation rate and variability of eukaryotic viruses: an analytical review. J Gen Virol 1987; 68: 2729-40.

57. Domingo E. RNA virus evolution and the control of viral disease. Prog Drug Res 1989; 33: 93-133.

58. Holmes E C, Worobey M, Rambaut A. Phylogenetic evidence for recombination in dengue virus. Mol Biol Evol. 1999; 16 : 405-9.

59. Farfan JA, Olson K E, Black W C, Gubler DJ, Beaty BJ. Rapid characterization of genetic diversity among twelve dengue-2 virus isolates by single-strand conformation polymorphism analysis. Am J Trop Med Hyg 1997; 57:416-22.

\section{Revista Biomédica}

